University of Wollongong

Research Online

Faculty of Engineering and Information

Faculty of Engineering and Information

Sciences - Papers: Part B

Sciences

2017

Experimental analysis of a water column and structure heave velocity relationship for a floating oscillating water column wave energy device

York Stanham

University of Wollongong, ys023@uowmail.edu.au

Timothy J. McCarthy

University of Wollongong, timmc@uow.edu.au

Brad Stappenbelt

University of Wollongong, brads@uow.edu.au

Follow this and additional works at: https://ro.uow.edu.au/eispapers1

Part of the Engineering Commons, and the Science and Technology Studies Commons

Research Online is the open access institutional repository for the University of Wollongong. For further information contact the UOW Library: research-pubs@uow.edu.au 


\title{
Experimental analysis of a water column and structure heave velocity relationship for a floating oscillating water column wave energy device
}

\author{
Abstract \\ This paper investigates the theoretical conclusions of a numerical analysis. The results are reproduced \\ experimentally using a two-dimensional model in a wave flume. The experimental set-up is conducted by \\ subjecting the model to waves with frequencies ranging from 0.2 to $2 \mathrm{~Hz}$. The heave velocities of the \\ structure and water column are calculated by differentiating the displacement of each with respect to \\ time. The experimental results confirm that the extent of the parametric relationship between the \\ structure heave velocity and oscillating water column heave velocity is linearly related to the power output \\ potential of the system and hence, can be used as a design tool for floating offshore wave energy \\ converters. It has also been determined that the extent of the parametric function is maximised when the \\ forcing frequency is between 90 and $100 \%$ of the natural frequency of the water column of the system in \\ question. This shows that the system efficiency is maximised when the waves cause resonance of the \\ water column compared to the ocean wave.

\section{Disciplines} \\ Engineering | Science and Technology Studies

\section{Publication Details} \\ Stanham, Y., McCarthy, T. J. \& Stappenbelt, B. (2018). Experimental analysis of a water column and \\ structure heave velocity relationship for a floating oscillating water column wave energy device. \\ Australian Journal of Mechanical Engineering, 16 (3), 230-237.
}




\section{Experimental Analysis of a Water Column and Structure Heave Velocity Relationship for a Floating Oscillating Water Column Wave Energy Device York Stanham, Timothy J McCarthy, Brad Stappenbelt \\ University of Wollongong, Faculty of Engineering and Information Sciences Wollongong, New South Wales, Australia \\ Email: ys023@uowmail.edu.au}

\begin{abstract}
This paper investigates the theoretical conclusions of a numerical analysis (Stanham et al (2016)). The results are reproduced experimentally using a two dimensional model in a wave flume.

The experimental setup is conducted by subjecting the model to waves with frequencies ranging from 0.2 to 2 $\mathrm{Hz}$. The heave velocities of the structure and water column are calculated by differentiating the displacement of each with respect to time.
\end{abstract}

The experimental results confirm that the extent of the parametric relationship between the structure heave velocity and oscillating water column heave velocity is linearly related to the power output potential of the system and hence, can be used as a design tool for floating offshore wave energy converters.

It has also been determined that the extent of the parametric function is maximised when the forcing frequency is between $90-100 \%$ of the of natural frequency of the water column of the system in question. This shows that the system efficiency is maximised when the waves cause resonance of the water column compared to the ocean wave.

KEY WORDS: Energy; power; oscillating water column; wave energy converter; oscillating wave energy converter; power capture, OWC, WEC.

\section{Introduction}

A background on oscillating water column wave energy devices has been covered in Stanham et al (2016). Oscillating water column wave energy devices have been subjected to numerous analytical and experimental analysis.

The basic mass-spring-damper model outlined by Stappenbelt and Cooper (2009) was recreated experimentally by Bayoumi et al. (2014). The model used by Bayoumi will be used as the basis for the model used for the experimental testing undertaken in this paper. Due to the work done by Bayoumi et al. (2014) in confirming such a model is a valid experimental setup, measurement of system characteristics such as damping, stiffness, and mass in an effort to validate the model is not essential to the conclusions of this paper.

The objective of this study is to investigate whether the conclusions of numerical analysis (Stanham et al. (2016)) regarding the axis lengths of the parametric ellipse relating the structure heave velocity to the water column heave velocity and also the ideal forcing period ratio of such a system are able to be reproduced experimentally.

\section{Methodology}

\section{Turbine damping and power production}

The turbine damping parameter will be modelled by an orifice above the water column. To simplify the model, the air is assumed to be incompressible. This assumption is valid as the pressure difference is in the range of $0.2-0.3 \mathrm{kPa}$. This difference is considered negligible when compared to the atmospheric pressure of $101.325 \mathrm{kPa}$. The turbine damping has also assumed to be linear; hence the relationship of the air flow through the orifice and the pressure difference should also be linear. The relationship between the pressure difference and air flow can be derived as follows. Figure 1 is used to define the directions of motion. 
Figure 1

The air flow rate through the orifice, $Q$, can be expressed as a function of the velocity of the air through the orifice, $V_{a}$, and the oscillating water column plan area, $A_{c}$ :

$$
Q=V_{a} A_{c}
$$

This can be expressed as a derivative of the function of the relative displacement between the oscillating water column and the floating structure $\left(x_{r}=z-x\right)$ (see Fig. 1):

$$
Q=\frac{d(z-x)}{d t} A_{c}=A_{c} \dot{x}_{r}
$$

Expressing this in terms of the pressure difference, $\Delta p$, the density of air, $\rho$, and the orifice area, $A_{o}$ and a correction factor/orifice coefficient, $K_{o}$.

$$
Q=K_{o} A_{o} \sqrt{\frac{2 \Delta p}{\rho}}
$$

Arranging for the pressure difference:

$$
\Delta p=\left(\frac{Q}{K_{o} A_{a}}\right)^{2} \frac{\rho}{2}
$$

The pressure difference relationship may be used to derive the turbine damping value. Damping is defined as a function of the vertical force, $F$, and oscillating water column velocity, $v_{c}$ :

$$
B=\frac{F}{v_{c}}=\frac{\Delta p A_{c}}{Q / A_{c}}
$$

Substituting $\Delta p$ from Eqn. 4 we get:

$$
B=\frac{Q \rho A_{C}^{2}}{2 K_{o}^{2} A_{o}^{2}}
$$

Expressing the damping value as a function of the oscillating water column velocity leads to the final expression for turbine damping:

$$
B=\frac{\rho A_{c}^{3}}{2 K_{o}^{2} A_{o}^{2}}\left|\dot{x}_{r}\right|
$$

Measuring the pressure differential and relative velocity of the oscillating water column the turbine damping can be determined.

\section{Experimental Description}

\section{Model}

The model consists of a floating Perspex box, mooring lines and an aluminium frame. The dimensions of the model are seen in Table 1.

\section{Table 1:}

The Perspex box is lined with expanded polystyrene. This has been done to increase the buoyancy of the device and to also provide a surface area for the heave force to act upon. The two dimensional aspect of the testing has been taken into consideration by only placing foam inserts on the front and rear elevations of the model. A rectangular shape has been chosen to reduce the transverse reflections. These reflections have been further reduced by extending the width of the model to $95 \%$ of the width of the tank. A photograph of the model moored to the frame placed in the testing tank is seen in Figure 2.

Figure 2

The model is held in location through a mooring system similar to that used by Fiorentini (2010). This system consists of four lines connected to the front of the model and four to the back. The top set of mooring lines are attached $50 \mathrm{~mm}$ from the vertical edge and $50 \mathrm{~mm}$ from the top of the model (Refer to Fig. 1). The bottom set of mooring lines is attached $50 \mathrm{~mm}$ from the vertical edge and $50 \mathrm{~mm}$ above the bottom of the 
model. The moorings lines are attached to an aluminium frame that is also placed in the wave tank. The frame has a width of $900 \mathrm{~mm}$ and length of $2550 \mathrm{~mm}$. This geometry gives the mooring lines a length of approximately $1025 \mathrm{~mm}$. The frame attachments can be moved vertically to adjust for different draft values if the weight of the structure is increased. This will allow the mooring lines to be horizontal at the structure's point of equilibrium.

The structure has been fitted with two heave plates $(100 \mathrm{~mm}$ by $500 \mathrm{~mm})$, one at the front and one at the back bottom edge. These heave plates are made of aluminium. The addition of the heave plates has allowed in increase in the structure bottom surface area without adding any significant mass to the system, hence the water column length has not been altered. This has been done to increase the natural heave period of the structure so the ratio of the structure natural period to water column natural period is within the guidelines established by Stappenbelt and Cooper (2009). The guidelines suggest that the structure natural period should be approximately 1.5 times the water column natural period. A photograph of one of the installed heave plates is seen in Figure 3.

\section{Figure 3}

Dimensioned images of the structure are seen in Figure 4.

\section{Figure 4}

\section{Data collection equipment}

Two wave probes have been installed within the model chamber, one at the front face and one at the back face. Two probes have been used to determine whether significant sloshing occurs within the chamber. This problem was not encountered during testing. These wave probes have been used to determine the heave displacement of the water column. A pressure sensor has been installed at the top of the model, half way between the orifice and short edge. The pressure sensor was used to measure the pressure differential between the chamber and the atmosphere. A laser sensor has tracked the heave displacement of the structure at a point in the middle of the top surface. These measurement tools and their installation location are shown in Figure 5.

\section{Testing method}

The model has been tested with single sinusoidal waves ranging from a frequency of 0.2 hertz to 1 hertz at $0.05 \mathrm{~Hz}$ intervals; at a wave amplitude of 40 millimetres. The simulations were run until the output voltages were repeating, this usually lasted around 40 seconds. Care was taken to avoid long running times because the flat face of the model caused reflected waves to eventually disrupt the incoming sinusoidal waves. The data was collected with LabView and processed in Microsoft Excel.

The natural period of the structure and water column were determined from the resulting RAO plots developed from this frequency sweep. The water column natural period was determined to be approximately 1.54 seconds and the structure natural period was determined to be 2.10 seconds. This produces a period ratio of 1.36 .

\section{Orifice damping linearization}

Linearisation of the orifice damping is essential because because theoretical programs such as WAMIT and OrcaFlex used in the numerical analysis (Stanham et al. (2016)) utilise linear a damping value during calculations. Fiorentini (2010) showed that 
introducing layers of nylon mesh of gauge 1 $\mathrm{mm}$ over the orifice was able to linearise the orifice damping. Fiorentini (2010) found that three layers of nylon mesh produced a sufficiently linear system. This conclusion has been tested on the model used in this paper.

The damping of the orifice is equal to the gradient of the function relating chamber pressure to the air flow rate through the orifice multiplied by the cross-sectional area of the water column. To achieve this plot, the structure has been oscillated by hand. The displacement of the water column and chamber pressure readings were collected as functions of time. The water column displacement was then used to calculate the water column velocity. Assuming the air is incompressible, the water column volume displacement should equal the air volume displacement and velocity. This has been undertaken for the 100 millimetre diameter orifice. The plot is seen in Figure 6.

\section{Figure 5}

\section{Results and Discussion}

Figure 6 shows good linearity $\left(\mathrm{R}^{2}=0.92271\right)$ between the air flow rate and chamber pressure. Using the gradient of the line of best fit the water column surface area the power takeoff damping can be estimated to be $6.68 \mathrm{~N} . \mathrm{s} / \mathrm{m}$. This value is used to determine the power out of the system in this paper.

\section{Figure 6}

\section{Measuring the RAOs}

The structure and water column response amplitude operators were produced by plotting the ratio of the maximum amplitude value to the wave amplitude against the period of the forcing wave. This output is seen in Figure 7. The RAO of each component shows two resonant peaks. This is expected in such a system and is also seen in the work done by Stappenbelt and Cooper (2009) and in numerical analysis paper by Stanham et al. (2016).

The resonant peak at approximately 1.54 seconds corresponds to the water column natural period and the resonant peak at approximately 2.10 seconds corresponds to the structure natural period. The ratio of these natural periods is 1.36 . This is similar to that used in the numerical analysis (1.38) (Stanham et al. (2016))

\section{Figure 7}

\section{Parametric Function Analysis}

Figure 8 details the structure-water column heave velocity data collected for a wave period of 1.54 seconds $(0.65 \mathrm{~Hz})$, and also for a wave period of 2.00 seconds $(0.5 \mathrm{~Hz})$. Velocities plotted in Figure 8 are absolute velocities. A wave with a period of two seconds has been chosen as this value is the closest value to the structure natural period that the wave maker was able to produce. These two wave periods roughly correspond to the natural period of the water column and structure respectively. The physical interpretation of this parametric plot can be summarised as the instantaneous heave velocity of the structure and water column at the same individual points in time. A graphical representation of this can be seen in the numerical analysis (Stanham et al. (2016)).

\section{Figure 8}

The experimental data does not resemble a typical ellipse like that seen in the numerical analysis (Stanham et al. (2016)). The reason of this is unclear but may be due to the build 
up of reflected waves within the tank as a result of the flat front surface of the model. An example how the extent of the parametric plot was quantified is seen in Figure 9. Figure 9 shows the parametric curve corresponding to the data collected at a wave period of 1.54 seconds $(0.65 \mathrm{~Hz})$. This corresponds with the oscillating water column natural period, hence this is a forcing period ratio

equal to one.

\section{Figure 9}

\section{Power production}

The power production as a function of the major (long) axis length is seen in Figure 10 and power production of the minor (short) axis length is seen in Figure 11. There exists a weak linear relationship for the experimental data compared to the theoretical relationship seen in the numerical analysis (Stanham et al. (2016)). This may be due to the high degree of reflected waves in the tank due to the flat face of the model. This caused irregularities in the forcing waves with lower wave periods ( $<2.00$ seconds).

This experimental setup showed a greater linear trend between the power production and the short axis (Fig. 11) length $\left(\mathrm{R}^{2}=0.73\right)$ than the long axis (Fig. 10) length $\left(\mathrm{R}^{2}=\right.$ $0.44)$, however both the long axis length $(\mathrm{P}=$ 0.0039) and short axis length $(\mathrm{P}=0.000012)$ have were determined to have a statistically significant linear relationship with the power production of the model at the $1 \%$ level of significance.

The derived data from the experiments in Figure 10 and Figure 11 show some data points that lie outside the expected trends of the data. These points lie at power output levels significantly higher than the majority of the data points. In Figure 10 these include the point corresponding to a power output of $\sim 70 \mathrm{~J}$ at an axis length of $\sim 0.275 \mathrm{~m} / \mathrm{s}$, and the points at a power output of $\sim 10 \mathrm{~J}$ at an axis length of $\sim 0.15 \mathrm{~m} / \mathrm{s}$. In Figure 11 the expected points are seen at a power output of $\sim 40 \mathrm{~J}$ at an axis length of $\sim 0.28 \mathrm{~m} / \mathrm{s}$ and a power output of $\sim 70 \mathrm{~J}$ at an axis length of $0.27 \mathrm{~m} / \mathrm{s}$.

These points of higher power output are the points derived from data collected at forcing periods equal to 1.67 seconds and 1.54 seconds. These values are close to the natural period of the water column hence more water column heave is experienced due to the discontinuity expected due to the resonant effect.

Figure 10

\section{Figure 11}

\section{Location of increased parametric plot extent}

The change in axis length of the parametric plot with respect to the natural period of the water column was undertaken, this is seen in Figure 12. The peak of the extent lies at a value close to that of the water column natural period (ratio $=1$ ) and stays elevated around the natural period of the structure (ratio $=1.36)$. This means that the system is able to produce more power when the water column natural period is matched to the forcing period of the wave and the dynamics of the system are such that the structure natural period is larger than water column natural period. This data is in agreement with the work of Stappenbelt and Cooper (2010), Bayoumi et al. (2014), and the numerical analysis (Stanham et al. (2016)).

Figure 12

\section{Axis gradient}

Investigation into the relationship between 
the gradient of the major (long) axis and the power production was also undertaken experimentally. The results showed little to no link between the long axis gradient and the expected power production. The data set corresponding to this analysis is seen in Figure 13. Figure 13 plots the power output as a function of the gradient of the major axis. The gradient is measure in degrees anticlockwise from the positive $x$-axis. The short axis gradient is approximately perpendicular to the long axis, hence the random nature of the results remains and the graph has not been plotted.

The experimental data, much the same as the theoretical data in the numerical analysis (Stanham et al. (2016)), showed that a large phase difference between the water column heave velocity and the structure heave velocity (gradient of $135^{\circ}$ ) is not essential to power production in a floating wave energy converter and cannot be attributed to the length of either the major or minor axis but is rather just a characteristic of the system setup at a particular forcing period. This is evident in the experimental analysis due to the lack of a large power output value corresponding to a gradient of $135^{\circ}$ in Figure 13.

Figure 13

\section{Phase Averaging}

Phase averaging the data to produce velocity plots across one wave cycle further supports the conclusions drawn in this study. Figure 14, Figure 15, and Figure 16 plots the absolute heave velocity of the oscillating water column and the heave velocity of the floating structure against the phase of each oscillation. Figure 14 is produced with a forcing frequency of $0.65 \mathrm{~Hz}$, Figure 15 with $0.5 \mathrm{~Hz}$, and Figure 16 with $0.4 \mathrm{~Hz}$. Figure 16 has been included here as an example of phase averaged data that does not align with either the oscillating water column natural period or the structure natural period.

Figure 14

Figure 15

Figure 16

Comparison of Figure $14-16$ show that the larger velocity differential is seen at forcing period ratios corresponding to the oscillating water column natural period (Figure 14), then the structure natural period (Figure 15), and finally values that do not align with either natural period (Figure 16).

Figures 14 - 16 supports the data shown in Figure 12. A higher velocity difference leads to longer elliptical axis lengths. Hence higher expected power outputs at those respective forcing periods. This conclusion is supported in Figure 10 and Figure 11.

\section{Conclusion and Recommendations}

The experimental data does not resemble a typical ellipse like that seen in the numerical analysis (Stanham et al. (2016)). It is believed that this is caused by the irregular waves produced due to a mixture of constructive and deconstructive interference from reflected waves at low wave period. Data collected at higher wave periods $(>2 s)$ is much smoother because these waves are able to pass through the system with little reflection. This effect can be seen by comparing the plots in Figure 8.

Despite this, this study has shown that the relationship between both the major and minor axis length and power output in an oscillating water column wave energy device and the how the length of the major and minor axes changes with forcing period ratios produced theoretically with WAMIT and 
OrcaFlex in the numerical analysis (Stanham et al. (2016)) can be reproduced experimentally. The experimental analyses have shown a scattered linear trend between the power output of a floating oscillating water column wave energy device and the length of the long axis of the ellipse relating the heave velocity of the structure to the heave velocity of the water column.

Therefore, the length of the long and short axis of the ellipse, or rather the extent of the parametric plot relating the structure heave velocity to the oscillating water column heave velocity, can be used as an indicator for potential OWC power production capabilities rather than the expected heave of the structure or water column with respect to the forcing wave. The maximum axis lengths have been shown to occur at a forcing period equal to the natural period of the water column. The lengths have also shown to be longer (but not maximised) when subjected to waves with forcing periods corresponding to the natural period of the structure. The axis length, and hence power output, remains elevated between these two points. With this in mind a separation between the natural period of the structure and water column is beneficial for power production in a floating oscillating water column wave energy converter.

The numerical and experimental analysis suggest that there is no discernible link between the gradient of the long axis of the ellipse and the power output production. This is also confirmed through the thought experiment seen in the numerical analysis (Stanham et al. (2016)).

Further research is needed into how the natural period ratio of the structure to the water column affects the axis lengths. It would be useful to determine if there is an upper limit of this ratio or if further separation shows a continued increase in axis length and hence power production.

\section{Acknowledgements}

This work was carried out with the financial support of an Australian Postgraduate Award, administered by the University of Wollongong.

The authors would also like to acknowledge the University of Wollongong technical staff for their help in the laboratory.

\section{References}

Bayoumi, S., Incecik, A. \& El-Gamal, H. (2014), 'Dynamic modelling of Spar-Buoy oscillating water column wave energy converter', Ships and Offshore Structures

Fiorentini, M. (2010), Evaluation of the frequency dependent parameters and optimization of a floating OWC device, Masters Thesis, University of Wollongong

Stanham, Y., McCarthy, T., Stappenbelt, B. 'Water column and structure heave velocity relationship for a floating oscillating water column wave energy device', Submitted for ISOPE 2016

Stappenbelt B, Cooper P. (2009). Mechanical model of a floating oscillating water column wave energy conversion device. Ann Bull Aust Inst High Energetic Mater. 1:34-45.

WAMIT, n.d.. WAMIT, Inc., Chestnut Hill,Massachusetts. 


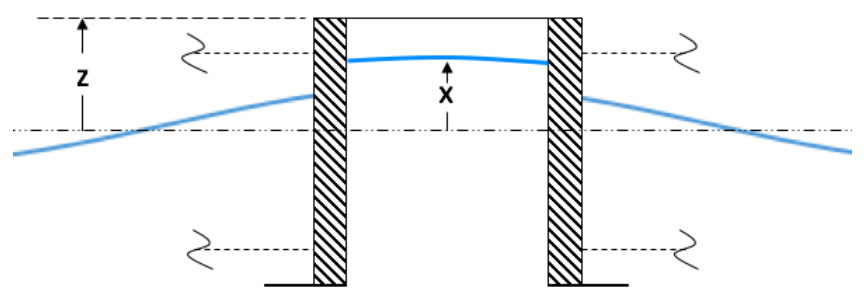

Figure 6 - Water column schematic

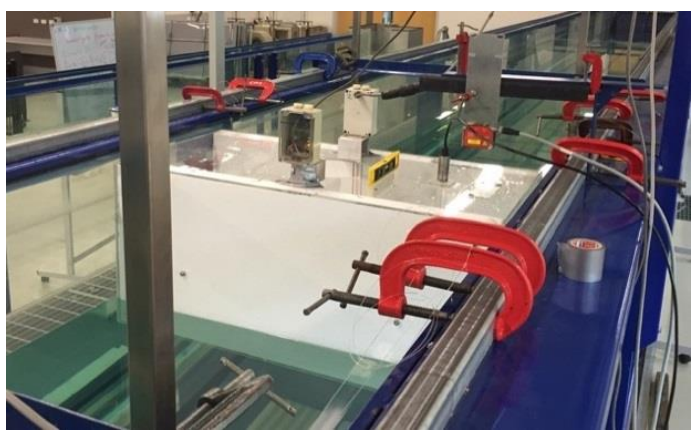

Figure 7 - Model in wave tank

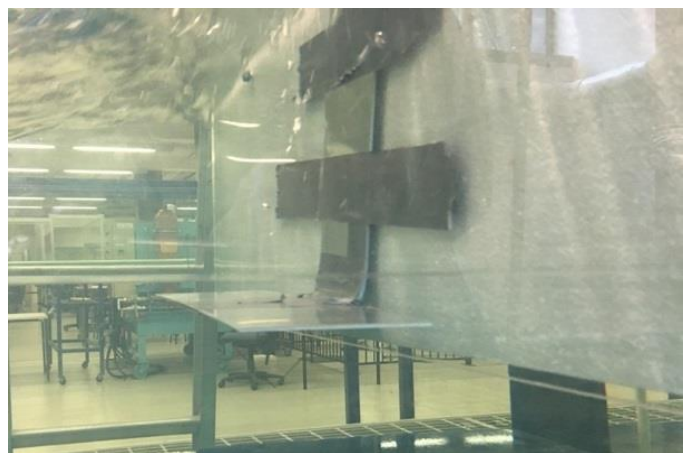

Figure 8 - Photograph of the front heave plate
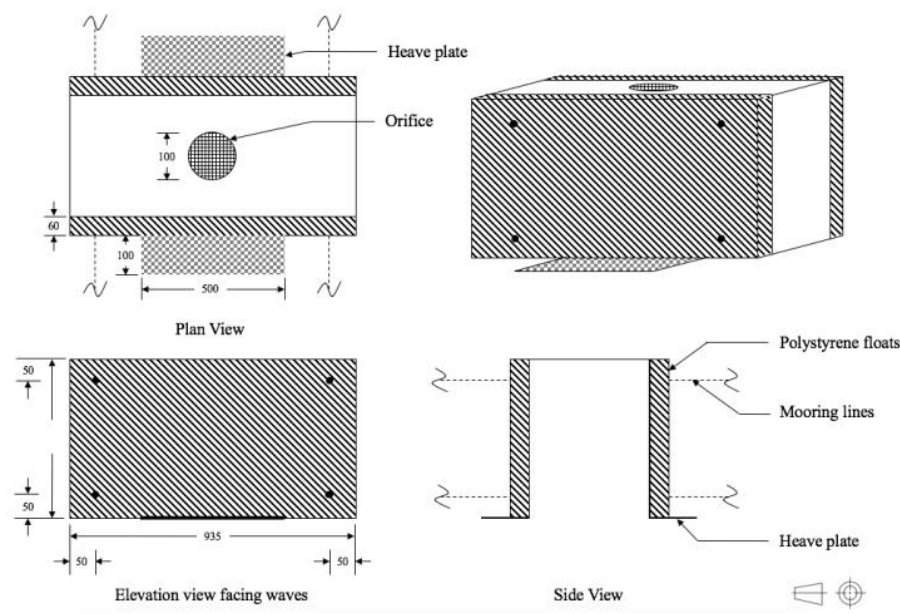

Figure 9 - Model drawings (not to scale) 


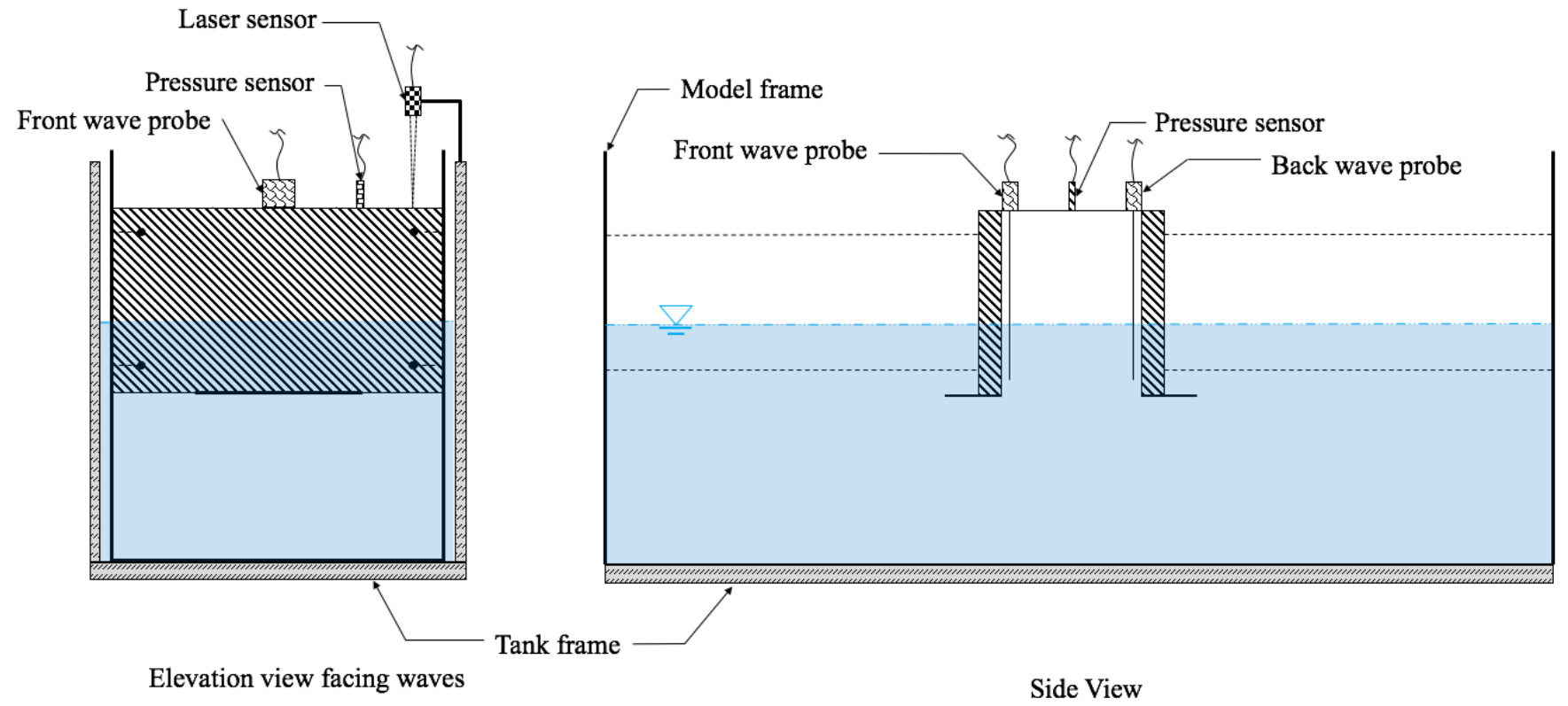

Figure 10 - Measurement tools installation locations

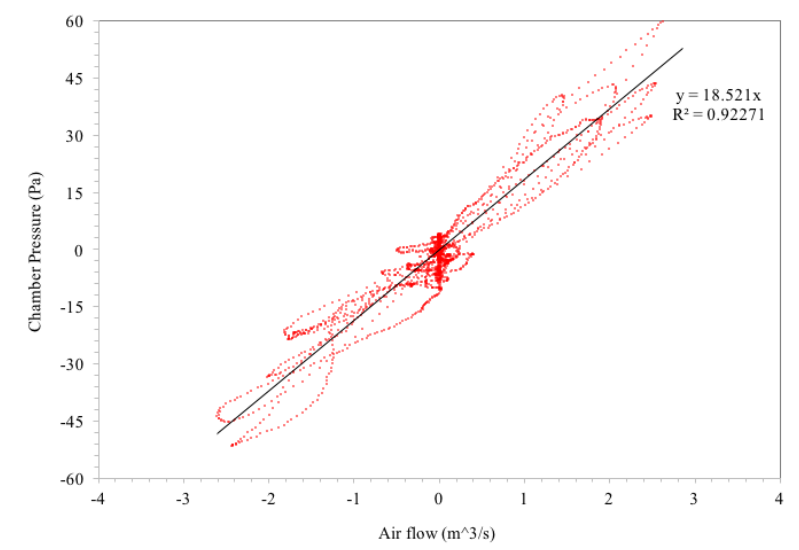

Figure 6 - Chamber pressure as a function of air flow rate through the $100 \mathrm{~mm}$ orifice

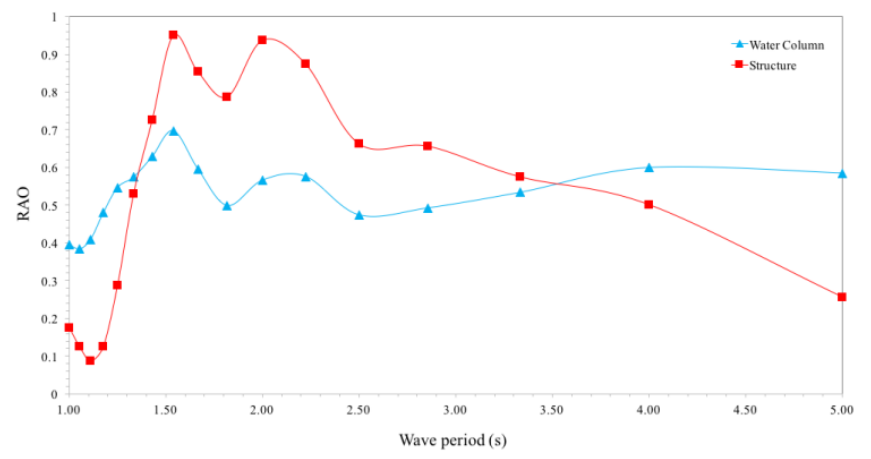

Figure 7 - Water column and structure response amplitude operators 


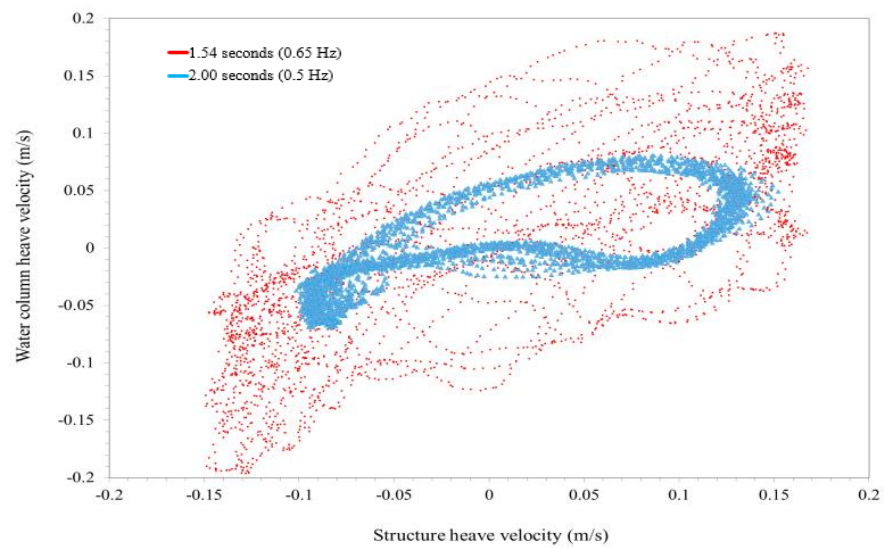

Figure 8 - Structure-water column parametric plot for a wave of 1.54 seconds $(0.65 \mathrm{~Hz})$ and 2.00 seconds $(0.50 \mathrm{~Hz})$

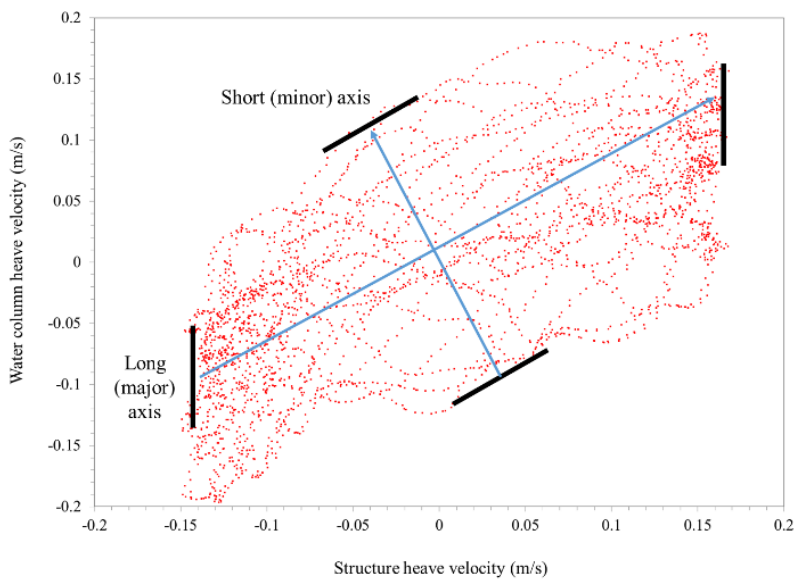

Figure 9 - Determining extent of the parametric function for data collected from a wave with period of 1.54 seconds $(0.65 \mathrm{~Hz})$.

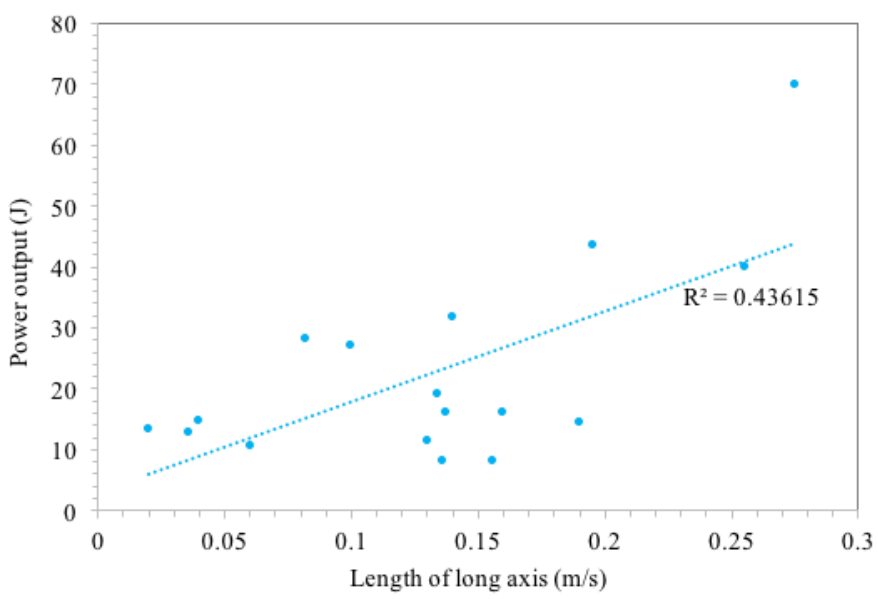

Figure 10 - Power production as a function of the major (long) axis length 


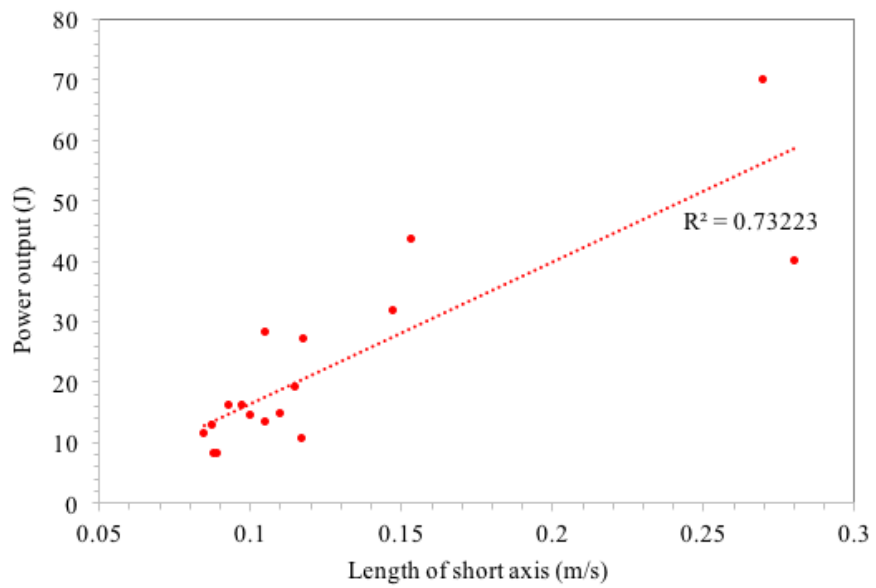

Figure 11 - Power production as a function of the minor (short) axis length

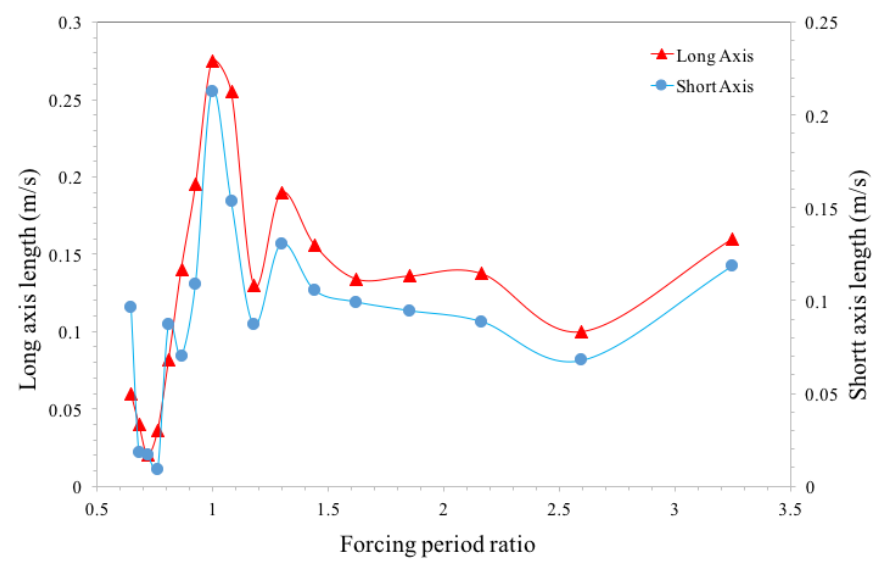

Figure 12 - Axis length as a function of the ratio of the forcing period to the water column natural period

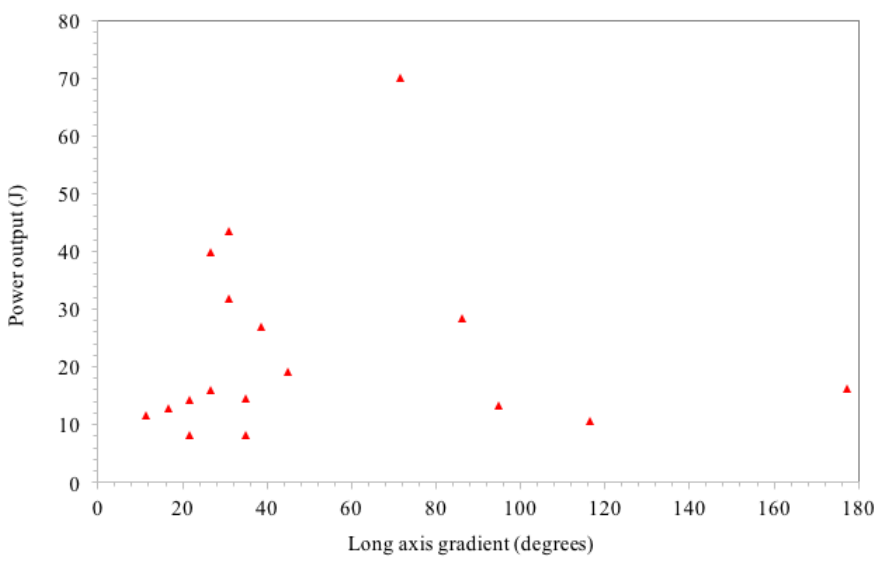

Figure 13 - Experimental power output as a function of the gradient of the long axis 


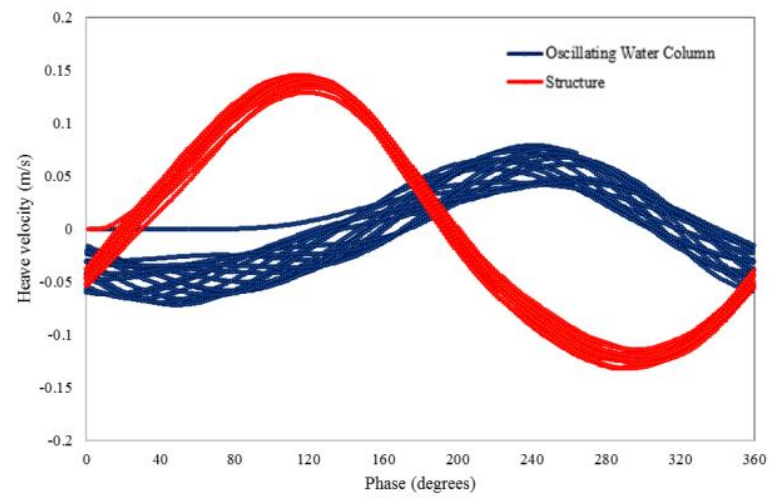

Figure 14 - Phase averaged heave velocity with a forcing frequency of $0.65 \mathrm{~Hz}$ (forcing period ratio of 1)

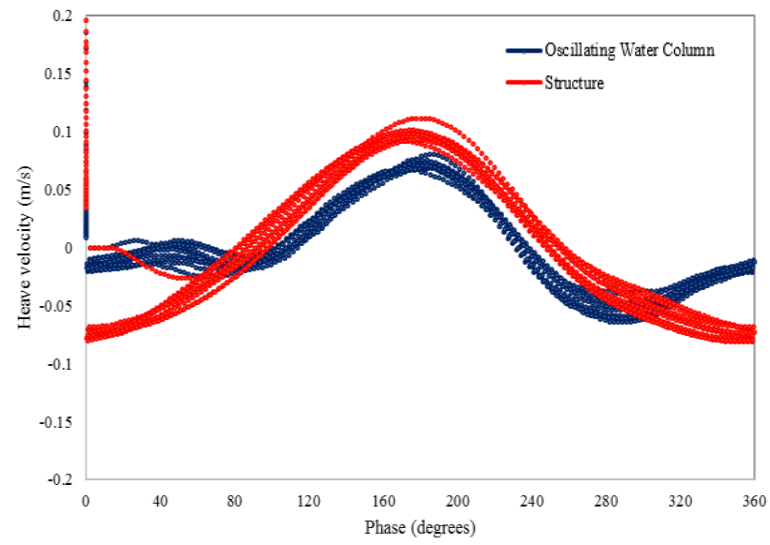

Figure 15 - Phase averaged heave velocity with a forcing frequency of $0.5 \mathrm{~Hz}$ (forcing period ratio of 1.3)

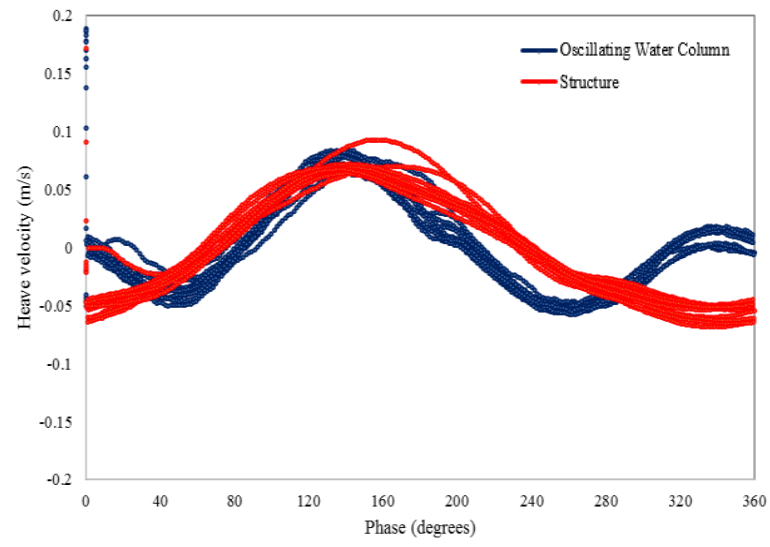

Figure 16 - Phase averaged heave velocity with a forcing frequency of $0.4 \mathrm{~Hz}$ (forcing period ratio of 1.6) 
Table 1: Model parameters

\begin{tabular}{|l|l|}
\hline Parameter & Value \\
\hline Width $(\mathrm{mm})$ & 935 \\
\hline Height $(\mathrm{mm})$ & 500 \\
\hline Length $(\mathrm{mm})$ & 500 \\
\hline Mass $(\mathrm{kg})$ & 13.8 \\
\hline Structure bottom surface area $\left(\right.$ no heave plates) $\left(\mathrm{mm}^{2}\right)$ & 106,750 \\
\hline Heave plate surface area $\left(\mathrm{mm}^{2}\right)$ & 100,000 \\
\hline Oscillating water column surface area $\left(\mathrm{mm}^{2}\right)$ & 360,750 \\
\hline Orifice diameter $(\mathrm{mm})$ & $200,100,50$ \\
\hline OWC/Chamber width $(\mathrm{mm})$ & 925 \\
\hline OWC/Chamber length $(\mathrm{mm})$ & 380 \\
\hline Measured OWC Natural Period $(\mathrm{s})$ & 1.54 \\
\hline Measured Structure Natural Period (s) & 2.10 \\
\hline
\end{tabular}

